\title{
Fragmentação e (de)composição espacial de uma realidade pós-moderna*
}

“... se há um domínio no qual a lógica ocidental de controle do mundo pela técnica fracassou, é bem a da cidade. Ela resiste: sua desordem é mais forte que as projeções ideais e os planos racionais. E é essa resistência que faz sua beleza."

- Christian de Portzamparc

\section{RESUMO}

A inevitável hibridização da cidade na contemporaneidade pode ser compreendida pela imagem mítica do labirinto. Partiremos das idéias de dúvida e adaptação para evocarmos a temática do espaço na sociedade atual.

\section{PALAVRAS-CHAVE}

- cidade

- espaço

- pós-modernidade

\section{ABSTRACT}

The inevitable hybridization of the city in contemporaneity can be understood through the mythical image of the labyrinth. We'll start from concepts like doubt and adaptation, in order to evoke the theme of space in our present society.

\section{KEY WORDS \\ - city \\ - space \\ - post-modernity}

\section{Tânia Rocha Pitta}

CEAQ e Núcleo Interdisciplinar de Estudos sobre o Imaginário
N otemos que a cidade, hoje, não é mais controlável. Certas favelas são um bom exemplo de um urbanismo que não se consegue mais dominar. As cidades atuais tornam-se inevitavelmente híbridas. Vivemos a era da dúvida, do contingente, do lugar, da adaptação, destaca Christian de Portzamparc, enquanto Michel Maffesoli evoca a temática do espaço, do localismo "afetual" e da tribo como sendo os fatores essenciais de compreensão da nossa contemporaneidade. Trata-se hoje, segundo Gilbert Durand, de encontrar a felicidade nos crematórios, ou seja, de aceitar a cidade tal como ela se faz.

A imagem do labirinto, obra realizada por Dédalo, está freqüentemente associada à cidade e ao urbanismo. Sua ambigüidade ajuda a compreender as razões pelas quais a temática do espaço é tão complexa.

Dédalo pode ser considerado como um personagem plural: ao mesmo tempo em que tem a confiança do rei Minos, ele o trai gerando uma vaca que vai favorecer o acasalamento entre a sua mulher e o touro. Foi também a Dédalo que o rei Minos, antes de saber da construção da vaca, encomenda o labirinto para trancar seu filho bastardo, o Minotauro. Percebemos a mesma lógica de ambigüidade ou de dualidade comentada no prefácio de Pierre VidalNaquet, segundo o qual "trata-se, para o herói mítico, não de ser isto ou aquilo, mas de explorar aquilo que Pascal chamava o 'entre dois', de conquistar a impossível conjunção do homem e da fera, do calor e do frio, do céu e da terra...". ${ }^{1}$ De fato, o labirinto é ambíguo, seu sentido muda segundo o espírito do tempo. Mesmo se sua imagem nos remete a um percurso emaranhado, à espiral, à imagem de uma concha, o importante é saber de que maneira podemos abordá-lo hoje.

Ainda que procuremos compreender a cidade, somos confrontados tanto com a geometria consciente dos lugares, quanto com a emoção transmitida pelas profundidades labirínticas. Como diz o arquiteto e artista Lima de Freitas: "abordar o labirinto equivale também a abordar aquilo que a psicologia chama de inconsciente. Falar de geometria, por um lado, é falar das estruturas ordenadoras evidentes para a consciência clara e pensante, manifestadas aos nossos olhos como forma, ordem espacial, número, matriz, invariável. Assim nós temos, de um lado, a desconstrução do caos primordial e, de outro, o próprio princípio solar de Logos". ${ }^{2}$

Eis então a dialética à qual somos confrontados: de um lado, inconsciente; de outro lado, a concepção espacial que procura hoje reduzir nosso peso 
existencial através de um jogo estético Conforme a época, a relação com a cidade varia e é exatamente nesse sentido que Christian de Portzamparc vai falar da terceira idade da cidade como sendo uma característica do nosso tempo.

Aquilo que ele vai chamar de primeira idade é a época clássica, em que a ordem urbana e a razão triunfam. A organização espacial é feita a partir do sistema de ruas com ilhotas fechadas, enquanto a identidade segue modelos em que a unidade da forma urbana reina numa harmonia homogênea.

Com a modernidade, que seria a segunda idade, assistimos a uma ruptura dessa topologia homogênea, o conceito de rua muda completamente para valorizar, sobretudo, a arquitetura. A construção obtém uma estética autônoma e torna-se um objeto independente do lugar. A cidade torna-se incontrolável... Seu habitante, até então inexistente, já que morto pela ordem imposta, ressuscita com sua monstruosa potência na desordem urbana causada pela modernidade.

A homogeneidade da forma, sendo um valor comum à época clássica e à época moderna, torna-se heterogênea em nossos dias. Encontramo-nos na contemporaneidade, nas cidades onde a desordem implica certa sensibilidade para melhor viver nos fragmentos dos lugares. Vivemos hoje numa forma de composição espacial que aceita a pluralidade da "granulometria urbana", 3 que faz alusão às diferentes dimensões dos lugares construídos. Vivemos hoje em cidades primeiramente, na época clássica, tecidas; em seguida, esburacadas pelos modernistas, e que procuram hoje ser recosturadas. O sensível ganhou espaço na penumbra dos tempos tornados vagos. Frouxos, na dimensão do suspenso, com tudo aquilo que remete à ambivalência, àquilo que não é fixo, como o percurso, como a música, com suas subidas e descidas, nas ruas ou na partitura musical.

Se o Minotauro foi primeiramente capturado com a ajuda do fio de Ariane e em seguida ressuscitado com toda sua cólera e seu aspecto monstruoso aquilo de um ser inaceitável já que plural, homem e animal ao mesmo tempo - ele parece ter-se suavizado em nossos dias, numa rítmica de paixões pela forma e, conseqüentemente, pelo ser, com sua parte animal acabando por ser aceita. Assim, o meio-homem, meio-animal, compõe com o ritmo das cidades em harmonia com as branduras do tempo, onde restando a faculdade de sonhar, de transfigurar a realidade. E, como diz o poeta: ${ }^{4}$

(resta) essa pequenina luz indecifrável a que às vezes os poetas tomam por esperança. Resta essa obstinação em não fugir do labirinto na busca desesperada de alguma porta quem sabe inexistente.

É a este núcleo terrestre que nós nos religamos.
Novamente, vivemos um retorno ao símbolo da terra, o qual foi caro a Dédalo quando ele construiu a vaca para o prazer de Pasiphaé ajudando a colocar no mundo um ser plural e quando constrói o labirinto, prisão daquele que ele ajudou a conceber, o Minotauro.

É na composição espacial que o "ritmo da vida" coloca seu ímpeto: veremos agora aquilo que a arquitetura de Christian de Portzamparc evoca através do projeto da Cidade da Música Roberto Marinho no Rio de Janeiro. Passamos do macro ao micro universo, o que seria um bom exemplo, já que é a construção de uma "cidade" com menos empecilhos e mais liberdade, sobretudo, quando o tema é a música.

Tendo por interesse a arquitetura moderna brasileira dos anos 50, época em que se vê emergir uma outra concepção do mundo baseada no aerodinamismo, na liberdade da forma, pela qual se procura dar a impressão de leveza, pelos pilotis em arquitetura, aquilo que dá a impressão que o prédio/casa flutua, estes são os efeitos do boom tecnológico marcado, sobretudo, pelo progresso da aviação. Christian de Portzamparc cria, no Rio de Janeiro, uma construção para a música onde a fragmentação do espaço convida o flâneur à percorrer o lugar como se estivesse no interior de uma cidade, composta por durações rítmicas, pluralidades espaciais, que fazem com que se sinta dentro de um microcosmo do mundo contemporâneo. Esse lugar, que une a música à forma arquitetural, evidencia um universo onde o espaço permite, por sua (de)composição espacial, a composição dos lugares de reencontro, tais como: a praça pública, o jardim tropical ou um manguezal, os terraços e mesmo as passarelas e escadas, lugares onde cada pessoa vê e é vista. Trata-se de uma grande casa sobre pilotis, com terraços de 10 metros de altura que permitem ter a sensação de flutuar. ${ }^{5} \mathrm{~A}$ dialética do estar em suspenso e do enraizamento remete-nos tanto à fuga do labirinto por Dédalo (e seu filho Icaro) que preparou as asas com ajuda de cera e de plumas quanto às profundezas pulsionais do inconsciente.

O local que abriga este micro-universo da música, de reencontros, de lazer, convida-nos a penetrar numa dinâmica formada então por diversos fragmentos espaciais, os quais são o fruto de uma forte reflexão sobre nossas sociedades contemporâneas, aquela das tribos e da aparência. Em 1995, em relação à Cidade da Música de Paris, Christian de Portzamparc já dizia que "o meio musical é feito de famílias, de tribos. Cada tipo de música é defendido por grupos de apaixonados que se aproximam dificilmente. [...] Procurei dar a cada uma destas populações sua geografia, sua casa" ${ }^{6}$

Como o fez notar Bertrand Beau, arquiteto apaixonado pela ópera, que escreveu o programa da Cidade da Música, o flâneur chega pelo jardim e para ter acesso ao terraço que se encontra a dez 
metros do solo deve subir uma rampa que seria como um esforço para chegar aos prazeres trazidos pela música, onde a felicidade é verdadeira nas formas curvas côncavas e convexas em concreto, num jogo de sombra e luz, onde as formas sinuosas dialogam com as colinas do Rio e com o mar. Esse grande volume que dá a impressão de flutuar está marcado pela estética, valorizando o hedonismo, o corpo, o lúdico (jogos, sonhos coletivos...).

Tudo se apresenta como um mundo completo em si mesmo: por sua fragmentação, cada lugar está em relação, e o espaço vazio entre eles permite viver no apogeu da aparência. Trata-se de um território que vale por ele mesmo, como diz Michel Maffesoli, "o território vale apenas se ele coloca em relação, se ele reconduz a outra coisa ou a outros lugares, e aos valores ligados a eles. [...] É neste sentido que o espaço pode ser uma base de exploração. Aquilo que nele retorna tornando-o flutuante, nebuloso, quase imaterial". ${ }^{7}$ Quando Christian de Portzamparc projeta um lugar, ele pretende "equilibrar as pontos de identificação e as surpresas, encadear as experiências contrastadas que, na percepção, vão se suceder e comunicar de maneira eufórica para viver no interior da construção. Estas noções de percurso, de duração, de espaço e de experiências emocionais contrastadas são fundamentais para mim e me reconduzem naturalmente à música". ${ }^{8}$

Falando da pintura e das leis da perspectiva, Gilbert Durand observa que quando "a pintura está cheia de arquiteturas e estátuas em 'trompe-l'oeil', [ela atinge] a arte total onde só faltaria a música". ${ }^{9}$ É essa arte total que a Cidade da Música no Rio procura alcançar. Lá, a arquitetura banhou-se na música e encontrou através de suas curvas um espírito lúdico longe dos impedimentos cartesianos.

Assim, a rigidez da forma é quebrada num clima composto de mar e de montanhas, numa cidade que já convidava ao culto do corpo e da ópera de rua, como gosta de dizer Joãozinho Trinta sobre o desfile das escolas de samba do carnaval do Rio. A Cidade da Música inscreve-se bem em nossa contemporaneidade e a partir de 2008, data prevista para sua abertura, ela estará pronta para acolher um público diverso. A fusão entre a arquitetura, a música e os diferentes grupos sociais presentes deverá ser total, para que seja verdadeira a pluridimensionalidade do aparato barroco que tem seu apogeu na arte de aparecer.

A sinergia entre o espaço e sociedade reconduz ao sentimento de pertença, de fazer parte de tal ou tal tribo, procurando partilhar as emoções, num jogo de reflexos onde aparecer diante dos outros se torna o luxo de toda transcendência do drama do amor, tema caro à ópera.

Constrói-se não somente a partir dos materiais, mas a partir da cultura. Poder-se-ia dizer que em Portzamparc a fragmentação é a tentação do plural, ou seja, a vontade de dividir suntuosamente os lu- gares criando os espaços fundos onde a música serve de aparato para colocar em evidência, como a beleza colorida de um vôo de uma arara, a vitalidade de um povo musical, onde até o aeroporto da cidade se chama Antônio Carlos Jobim. mfamecos

\section{NOTAS}

* Texto traduzido do francês por Juliana Tonin. (doutoranda PUCRS/bolsista CNPq)

1 Doublé Dédale, préface du livre de Françoise Frontisi-Ducroux. Dédale, mythologie de l'artisan en Grèce ancienne. Voir aussi : Gilbert Durand, "Polysémie de l'objet symbolique, Le vase de verre et le labyrinthe » in Mythe, thèmes et variations.

2 FREITAS, Lima de. Das Geometrias labirinticas. Revista ICALP, vol. 2/3, 1985, 69-81.

3 Em relação à granulometria urbana, ver os seminários de Christian de Portzamparc no Collège de France.

4 Extraído do poema O Haver de Vinicius de Moraes.

5 Projetado pelo paisagista Fernando Chacel.

6 GALLIERI, Alain et Guilheux, Alain, Entretien avec Christian de Portzamparc, Résonance $\mathrm{n}^{\circ} 7$, mars 1995 Copyright (C) Ircam - Centre GeorgesPompidou 1995.

7 MAFFESOLI, Michel. Du nomadisme, vagabondages initiatiques. Le livre de poche. Paris: 1997, p. 81.

8 GALLIERI, Alain et Guilheux, Alain, Entretien avec Christian de Portzamparc, Résonance $\mathrm{n}^{\circ} 7$, mars 1995 Copyright $(\odot$ Ircam - Centre GeorgesPompidou 1995.

9 DURAND, Gilbert. Beaux arts et archétypes, p. 59. 